\title{
A Study of $\mathrm{CO}_{2}$ Methanation over Ni-Based Catalysts Supported by CNTs with Various Textural Characteristics
}

\author{
Yanyan Feng, ${ }^{1,2}$ Wen Yang, ${ }^{1,2}$ and Wei $\mathrm{Chu}^{2}$ \\ ${ }^{1}$ Department of Chemistry and Bioengineering, Guilin University of Technology, Guilin 541006, China \\ ${ }^{2}$ Department of Chemical Engineering, Sichuan University, Chengdu 610065, China \\ Correspondence should be addressed to Wei Chu; chu1965chengdu@163.com
}

Received 18 July 2015; Revised 15 September 2015; Accepted 29 September 2015

Academic Editor: Moshe Sheintuch

Copyright (c) 2015 Yanyan Feng et al. This is an open access article distributed under the Creative Commons Attribution License, which permits unrestricted use, distribution, and reproduction in any medium, provided the original work is properly cited.

\begin{abstract}
This work studied the influence of textural characteristics of CNTs on catalytic performance of Ni/CNTs for $\mathrm{CO}_{2}$ methanation. The CNTs supports were prepared by chemical vapor deposition method using $\mathrm{Ni} / \mathrm{MgO}$ catalysts, and acetonitrile and ethanol were used as carbon sources, respectively. The Ni/CNTs catalysts were prepared via impregnation method and characterized by $\mathrm{X}$-ray diffraction (XRD), $\mathrm{N}_{2}$ adsorption/desorption, and temperature-programmed reduction $\left(\mathrm{H}_{2}-\mathrm{TPR}\right)$ techniques. The results indicated that the textural characteristics of CNTs supports significantly impacted on the catalytic performance of Ni/CNTs. The catalyst Ni/CNTs-E (CNTs using ethanol as carbon source) had good reducibility, high specific surface area, and moderate defects, resulting in higher $\mathrm{CO}_{2}$ conversion and $\mathrm{CH}_{4}$ yield, followed by Ni/CNTs-C (commercial CNTs) and Ni/CNTs-A (CNTs using acetonitrile as carbon source). Based on Arrhenius formula, activation energies of the catalysts were calculated and were found decreased for Ni/CNTs-A and Ni/CNTs-E.
\end{abstract}

\section{Introduction}

$\mathrm{CO}_{2}$ emissions increased dramatically due to human activities, including power generation, transportation, deforestation, and fossil fuels [1-3]. The $\mathrm{CO}_{2}$ recycling has become an important topic in recent years, and a lot of researches have been conducted [4-6]. As $\mathrm{CO}_{2}$ is one of the main contributors to greenhouse effect and hence to climate change, there is a growing interest in its use as a feedstock in chemical processes $[3,7]$, wherein $\mathrm{CO}_{2}$ capture and storage (CCS) and $\mathrm{CO}_{2}$ chemical conversion [8] have attracted wide interests. It is important to convert $\mathrm{CO}_{2}$ to fuels or raw materials which must be also easily transportable. $\mathrm{CH}_{4}$ is suitable for this because it benefits from the existing infrastructure for transport and storage of natural gas [9-11].

$\mathrm{CO}_{2}$ methanation $\left(\mathrm{CO}_{2}+4 \mathrm{H}_{2} \rightarrow \mathrm{CH}_{4}+2 \mathrm{H}_{2} \mathrm{O}\right)$ is one of the most important methods and has been studied extensively using different types of metals and supports [3, 12]. The $\mathrm{CO}_{2}$ methanation reaction is exothermic, and an eight-electron process is required to reduce the fully oxidized carbon to $\mathrm{CH}_{4}$ with an appropriate catalyst. $\mathrm{Ni}[1,13-16], \mathrm{Ru}$ $[2,3]$, and $\mathrm{Rh}[7,12,17,18]$ based catalysts have been proved to have good catalyst activities in $\mathrm{CO}_{2}$ methanation [19], and nickel based catalysts have been extensively investigated under varying experimental conditions for its low price and high activity. Currently, main supports of the catalysts are activated carbon (AC) [18], $\mathrm{Al}_{2} \mathrm{O}_{3}[7,17,18], \mathrm{SiO}_{2}, \mathrm{ZrO}_{2}$ $[1,13,16]$, molecular sieve, $\mathrm{Ni} / \mathrm{Ce}_{x} \mathrm{Zr}_{1-x} \mathrm{O}_{2}$ [5], $\mathrm{TiO}_{2}$ [12], $\mathrm{SiC}$ [15], and $\mathrm{CeO}_{2}$ [20].

Carbon nanotubes (CNTs), as a novel nano-carbon catalyst support, have been widely used due to their interesting mechanical and electronic properties and stability [21-23]. The enhanced activity of CNTs systems has been attributed to an electronic interaction between the metal and the support, as well as the overflow effect of hydrogen [24, 25]. The effect of CNTs with various textural characteristics and defects has not been studied in detail for $\mathrm{CO}_{2}$ methanation. It has been shown that in the case of catalysts supported by CNTs with high specific surface area, highly dispersed metal of small particles was easily formed and more active than large metal ensembles. For catalysts supported by CNTs with more defects, it was advantageous to promote the metal loading and the dispersion of active components. 
The present work aimed to clarify some aspects of the activity of nickel based catalysts supported by CNTs with various textural characteristics toward $\mathrm{CO}_{2}$ methanation. The objective was to study the effect of textural characteristics on the catalysts and their catalytic activity for $\mathrm{CO}_{2}$ methanation at different temperatures. The synthesized catalysts were characterized by X-ray diffraction (XRD), $\mathrm{N}_{2}$ adsorption/desorption, and temperature-programmed reduction $\left(\mathrm{H}_{2}-\mathrm{TPR}\right)$ techniques, respectively.

\section{Experimental}

2.1. Catalysts Preparation. The CNTs supports were prepared by chemical vapor deposition (CVD) method using $\mathrm{Ni} / \mathrm{MgO}$ catalysts, and acetonitrile and ethanol were used as carbon sources, respectively. The $\mathrm{Ni} / \mathrm{MgO}$ catalyst was prepared by citrate complex method. $\mathrm{Ni}\left(\mathrm{NO}_{3}\right)_{3} \cdot 6 \mathrm{H}_{2} \mathrm{O}$ and $\mathrm{Mg}\left(\mathrm{NO}_{3}\right)_{2} \cdot 6 \mathrm{H}_{2} \mathrm{O}$ were mixed in a citric acid aqueous solution, stirred and gelated at $70^{\circ} \mathrm{C}$. After drying at $120^{\circ} \mathrm{C}$ overnight, the dried gel was calcined at $500^{\circ} \mathrm{C}$ for $3 \mathrm{~h}$ in air to get the $\mathrm{Ni} / \mathrm{MgO}$ catalyst. The loading of $\mathrm{Ni}$ on the catalyst was kept at $50 \mathrm{wt}$ \%. To grow CNTs, $100 \mathrm{mg}$ of catalyst powder was dispersed on boat and was then placed in a horizontal quartz reactor. Firstly, the catalyst powder was reduced in situ in $\mathrm{H}_{2}$ at $550^{\circ} \mathrm{C}$ for $1 \mathrm{~h}$. Subsequently, the sample was heated to $650^{\circ} \mathrm{C}$ in flowing $\mathrm{N}_{2}$ and then bubbled the acetonitrile and ethanol for $1 \mathrm{~h}$. After $1 \mathrm{~h}$ of reaction, the obtained CNTs were cooled to room temperature in a $\mathrm{N}_{2}$ atmosphere. The CNTs were further purified in $100 \mathrm{~mL}$ of concentrated $\mathrm{HCl}$ at room temperature for $12 \mathrm{~h}$. After purification, the CNTs were filtered and washed with deionized water until the $\mathrm{pH}$ of the filtrate was around 7.0. Finally, the product was dried at $100^{\circ} \mathrm{C}$ overnight and labeled as "CNTs-A" and "CNTs-E," where A and $\mathrm{E}$ represented the as-prepared CNTs using acetonitrile and ethanol as carbon source, respectively. For comparison, the commercial CNTs purchased from the Chengdu Organic Chemical Limited Company in China were applied and named as "CNTs-C."

The catalysts Ni/CNTs-A, Ni/CNTs-E, and Ni/CNTs$\mathrm{C}$ were prepared via impregnation method. An aqueous solution of $\mathrm{Ni}\left(\mathrm{NO}_{3}\right)_{2}$ was prepared by dissolving $1.19 \mathrm{~g}$ $\mathrm{Ni}\left(\mathrm{NO}_{3}\right)_{2} \cdot 6 \mathrm{H}_{2} \mathrm{O}$ into $4.0 \mathrm{~mL} \mathrm{H} \mathrm{H}_{2} \mathrm{O}$. Next, $1.76 \mathrm{~g}$ of CNTs sample was impregnated with the $\mathrm{Ni}\left(\mathrm{NO}_{3}\right)_{2}$ solution and stirred at room temperature for $2 \mathrm{~h}$ and then evaporated to dryness at an $80^{\circ} \mathrm{C}$ water bath. The impregnated Ni/CNTs (Ni $12 \mathrm{wt} . \%)$ were dried at $110^{\circ} \mathrm{C}$ for $12 \mathrm{~h}$ and calcined in $\mathrm{N}_{2}$ at $450^{\circ} \mathrm{C}$ for $3 \mathrm{~h}$. The catalyst $\mathrm{Ni} / \mathrm{AC}$ (using activated carbon as the support) was prepared with aqueous solution of $\mathrm{Ni}\left(\mathrm{NO}_{3}\right)_{2}$ by the same method.

2.2. Catalytic Activity Evaluation. The catalytic activity measurement was conducted under atmospheric pressure in a fixed-bed reactor with an internal diameter of $6 \mathrm{~mm} .100 \mathrm{mg}$ of catalyst was loaded into the reactor and reduced with $\mathrm{H}_{2}$ at $450^{\circ} \mathrm{C}$ for $1 \mathrm{~h}$ prior to catalytic evaluation. The $\mathrm{CO}_{2}$ methanation reaction was performed at various reaction temperatures using a mixture of $\mathrm{H}_{2}$ and $\mathrm{CO}_{2}$ at molar ratio of 4 . Effluent gases from the reactor were analyzed online by a SC-200 model gas chromatograph with a TDX-01 column and a thermal conductivity detector (TCD). The length and temperature of column were $2.0 \mathrm{~m}$ and $80^{\circ} \mathrm{C}$, while the detector temperature was $60^{\circ} \mathrm{C}$, and the retention times of $\mathrm{H}_{2}, \mathrm{CO}, \mathrm{CH}_{4}$, and $\mathrm{CO}_{2}$ were $0.9 \mathrm{~min}, 2.5 \mathrm{~min}, 6.0 \mathrm{~min}$, and $10.5 \mathrm{~min}$, respectively.

2.3. Characterization. $\mathrm{N}_{2}$ adsorption/desorption isotherms were measured at $77 \mathrm{~K}$ with a Quantachrome Nova 1000e apparatus using an automated gas sorption system. Prior to the measurement, the sample was degassed at $120^{\circ} \mathrm{C}$ for $3 \mathrm{~h}$. The specific surface areas $\left(S_{\mathrm{BET}}\right)$ of the catalysts were determined using the BET equation, and the total pore volume $\left(V_{t}\right)$ was calculated from the volume of nitrogen held at $P / P_{0}=0.98 \sim 0.99$. Pore size distributions (PSDs) were estimated using the DFT (Density Functional Theory) equation.

The weight change of the sample was determined with a thermogravimetric analyzer (TGA Q500). In this protocol, $10 \mathrm{mg}$ sample in the TGA was kept at room temperature for about $30 \mathrm{~min}$, and then it was heated up to $900^{\circ} \mathrm{C}$ with a heating rate of $10^{\circ} \mathrm{C} / \mathrm{min}$ in the air.

Raman spectroscopy measurements of the samples were obtained with a Raman microspectrometer (LabRAM HR) that used an argon laser as the excitation $(\lambda=532 \mathrm{~nm})$. The spectra were recorded in the wave number range of $400-4000 \mathrm{~cm}^{-1}$ with typical exposure times of $2 \mathrm{~s}$. During the analysis, at least four tests were performed on different sections of each individual sample.

Phase analysis was performed using power X-ray diffraction (XRD) technique. The X-ray diffraction patterns were carried on X-ray diffraction apparatus (D/MAX-2500, Rigaku Company) with $\mathrm{Cu} \mathrm{K} \alpha(50 \mathrm{KV}, 100 \mathrm{~mA})$ radiation.

Temperature-programmed reduction $\left(\mathrm{H}_{2}-\mathrm{TPR}\right)$ experiments were carried out in a fixed-bed reactor. $100 \mathrm{mg}$ sample was loaded in the middle of the reactor tube. The temperature of the reactor was raised from $100^{\circ} \mathrm{C}$ to $800^{\circ} \mathrm{C}$ at a heating rate of $10^{\circ} \mathrm{C} / \mathrm{min}$ under $5 \% \mathrm{H}_{2} / 95 \% \mathrm{~N}_{2}$ with a flow rate of $30 \mathrm{~mL} / \mathrm{min}$. The $\mathrm{H}_{2}$ consumption was analyzed online by a SC-200 gas chromatograph with a thermal conductivity detector (TCD).

\section{Results and Discussion}

3.1. Characterization of CNTs. Figure 1(a) showed the $\mathrm{N}_{2}$ adsorption/desorption isotherms obtained on CNTs samples. These isotherms were type III, that is, the obviously increasing uptakes at the high relative pressure values. It was obvious that the isotherms of samples dramatically increased on reaching a relative pressure of unity. The isotherms exhibited remarkable hysteresis loops at higher relative pressure values $\left(P / P_{0}>0.4\right)$. Moreover, the adsorption volume of sample CNTs-E was the highest among the three samples, while the adsorption volume of CNTs-A was the lowest. The pore size distribution (PSD) computed with the DFT method was displayed in Figure 1(b). In order to make the graph full scale, the maximum value on the $x$-axis was $35 \mathrm{~nm}$. The CNTs containing larger pores were produced. The pore diameter range presented in Figure 1(b) was typical of mesoporous materials. 


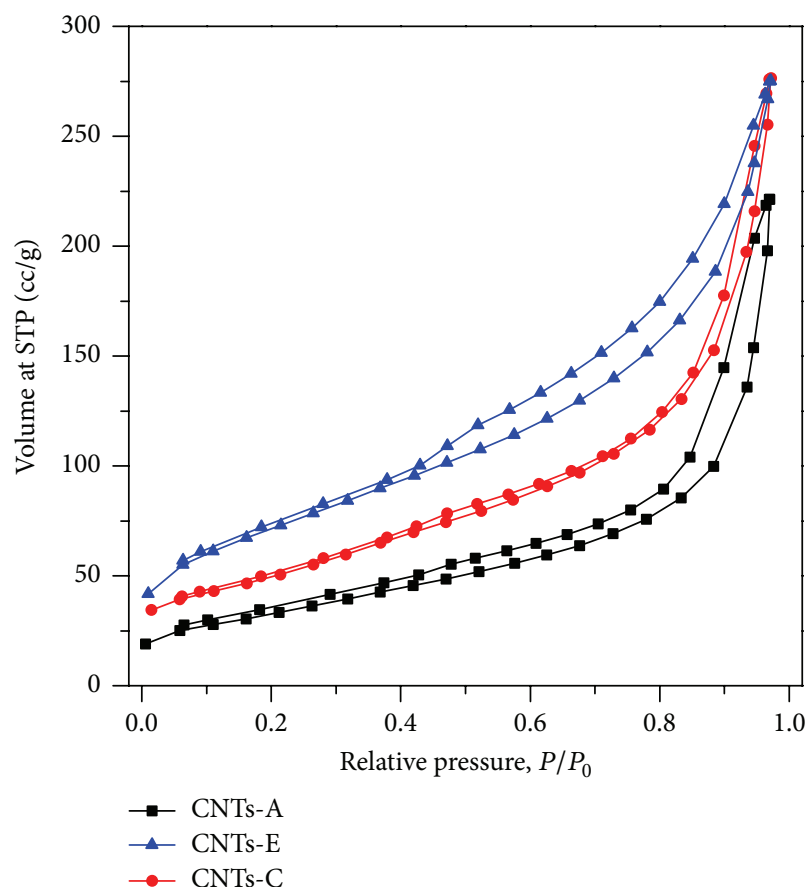

(a)

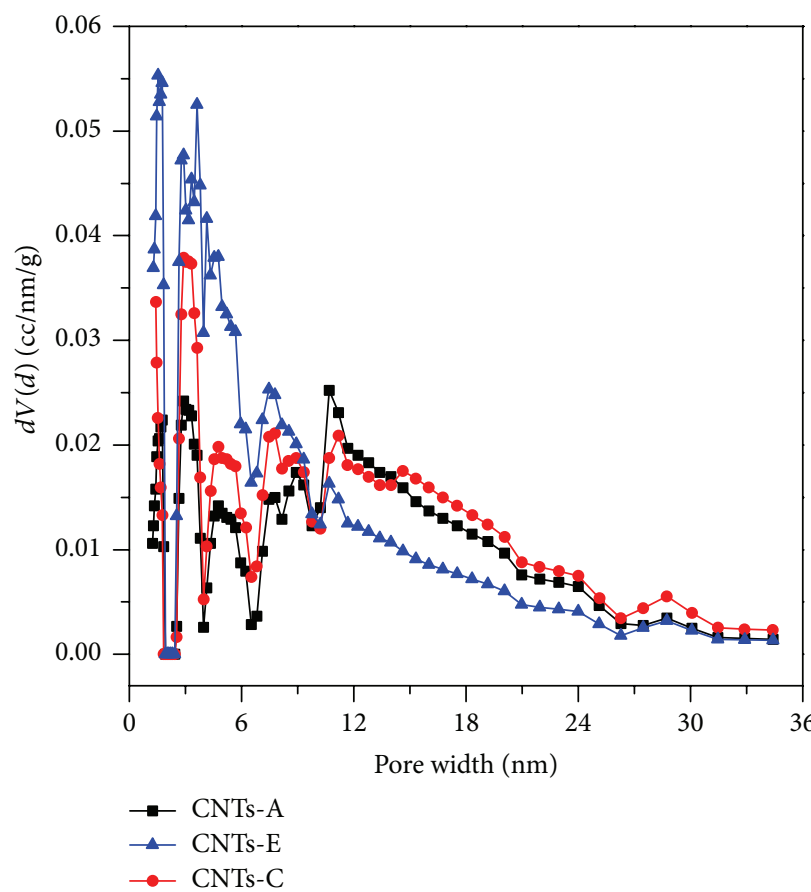

(b)

FIGURE 1: $\mathrm{N}_{2}$ adsorption/desorption isotherms (77 K) (a) and pore size distributions (b) obtained applying the DFT equation corresponding to the CNTs samples.

Table 1 presented the textural parameters for the samples. The variation of carbon sources led to differences in the $S_{\mathrm{BET}}$, total pore volume, and average pore diameter $\left(D_{P}\right)$. Among the samples, the CNTs-E displayed the highest $S_{\mathrm{BET}}$ and lowest $D_{P}$, indicating that the porosity of CNTs-E was developed. Compared with others, the CNTs-A sample had the lowest $S_{\mathrm{BET}}$, being $65.98 \%$ and $46.48 \%$ of the CNTs-C and CNTs-E, respectively.

Thermogravimetric analysis (TGA) has been widely used to analyze types of carbon materials. Typically, those losses were attributed to the removal of amorphous carbon (300 $400^{\circ} \mathrm{C}$ ), CNTs $\left(400 \sim 700^{\circ} \mathrm{C}\right)$, and massive graphite carbon (> $700^{\circ} \mathrm{C}$ ). Figure 2(a) showed the weight loss of the purified products during heating in air. Compared with CNTs-A and CNTs-E, the CNTs-C possessed most of the weight loss $(97.3 \%)$ at $400 \sim 700^{\circ} \mathrm{C}$, indicating high purity of the CNTs. The weight loss was $90.0 \%, 91.8 \%$, and $97.3 \%$ for CNTs-A, CNTs-E, and CNTs-C, respectively. It was observed that the temperature of initial weight loss was $440^{\circ} \mathrm{C}$ for CNTs-A, $478^{\circ} \mathrm{C}$ for $\mathrm{CNTs}-\mathrm{E}$, and $618^{\circ} \mathrm{C}$ for $\mathrm{CNTs}-\mathrm{C}$, suggesting that the grown CNTs-C were more highly graphitic with higher initial weight loss temperature.

Raman spectra of the three samples, shown in Figure 2(b), presented a prominent $D$-band (defects) at $1350 \mathrm{~cm}^{-1}$ and a less-intense $G$-band at $1580 \mathrm{~cm}^{-1}$, attributed to a perfect graphite structure $[10,26,27]$. It was clear that the $D$ band intensity was higher than the $G$-band intensity and CNTs-C had a better developed $G$-band, as well as the $D$ band. The increase of the G-band relative intensity indicated an improvement of the crystallite orientation, while
TABLE 1: Structural characteristics of the studied samples.

\begin{tabular}{lccc}
\hline Sample & $S_{\mathrm{BET}}\left(\mathrm{m}^{2} / \mathrm{g}\right)$ & $V_{t}\left(\mathrm{~cm}^{3} / \mathrm{g}\right)$ & $\begin{array}{c}\text { Average pore } \\
\text { diameter }(\mathrm{nm})\end{array}$ \\
\hline CNTs-A & 118.1 & 0.342 & 11.59 \\
CNTs-C & 179.0 & 0.427 & 9.55 \\
CNTs-E & 254.1 & 0.425 & 6.69 \\
\hline
\end{tabular}

the increasing $D$-band relative intensity suggested more defects and an increasing amount of disordered structure of the sample. The pertinent Raman parameter, $I_{D} / I_{G}$, which has already been mentioned to account for the degree of structural order, as displayed in Figure 2(b), confirmed the structure development of the samples $\left(I_{D} / I_{G}\right.$ values of CNTsA, CNTs-E, and CNTs-C were 1.09, 1.27, and 1.62, resp.).

3.2. Characterization of Catalysts. The $\mathrm{N}_{2}$ adsorption/desorption isotherms and pore size distributions were presented in Figure 3. Table 2 summarized the textural parameters for the catalysts. As shown in Figure 3(a), the adsorption volumes of $\mathrm{Ni} / \mathrm{CNT}$ s were lower than that of $\mathrm{Ni} / \mathrm{AC}$ owing to the developed microporosity (Figure 3(b)) of AC. When Ni was added into CNTs and AC, the adsorption volumes have decreased for the catalysts, since dispersed $\mathrm{Ni}$ was partly embedded into the pores of Ni/CNTs and Ni/AC. Table 2 presented the data for the specific surface areas and total pore volume of the catalysts. The specific surface areas of the catalysts in decreasing order were as follows: $\mathrm{Ni} / \mathrm{AC}>$ $\mathrm{Ni} / \mathrm{CNTs}-\mathrm{E}>\mathrm{Ni} / \mathrm{CNTs}-\mathrm{C}>\mathrm{Ni}$ /CNTs-A. Compared with the 

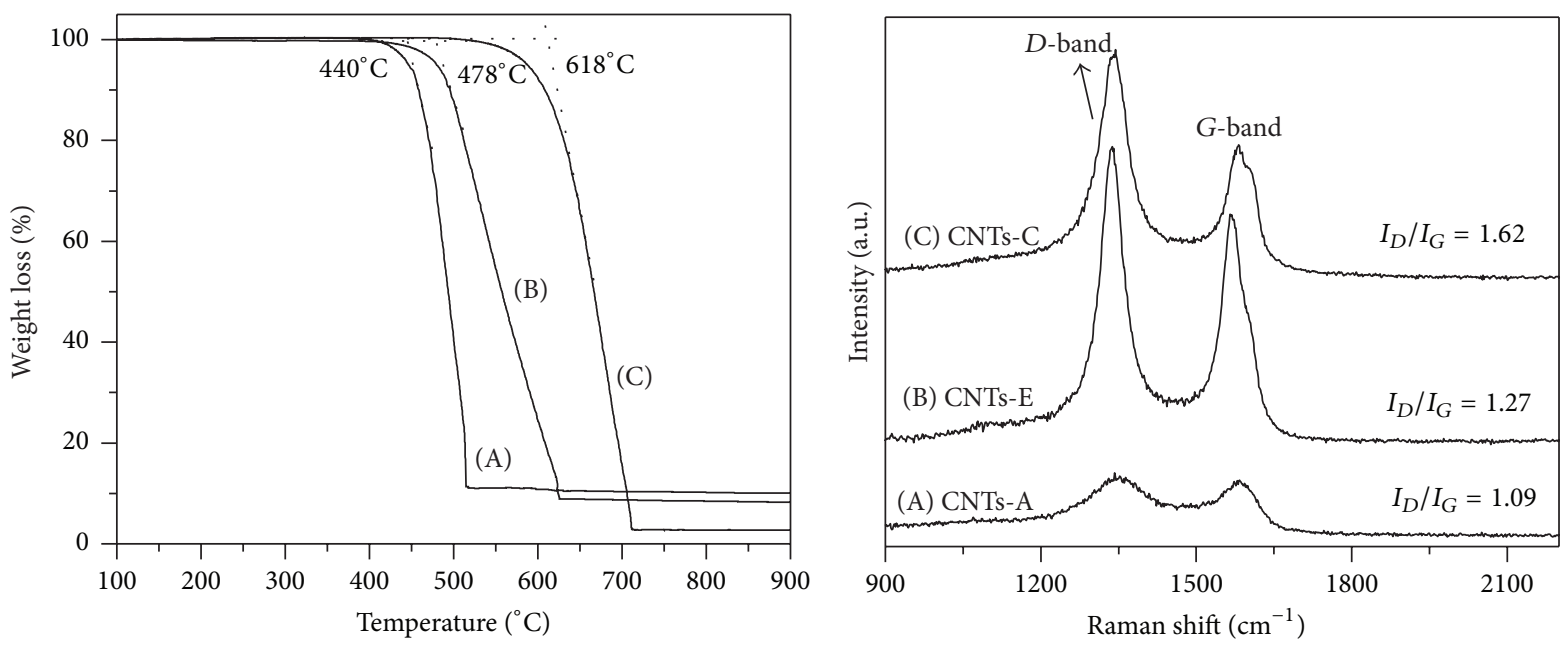

(A) CNTs-A

(B) CNTs-E

(C) CNTs-C

(a)

(b)

Figure 2: TG curves (a) and Raman spectra (b) of the CNTs samples.

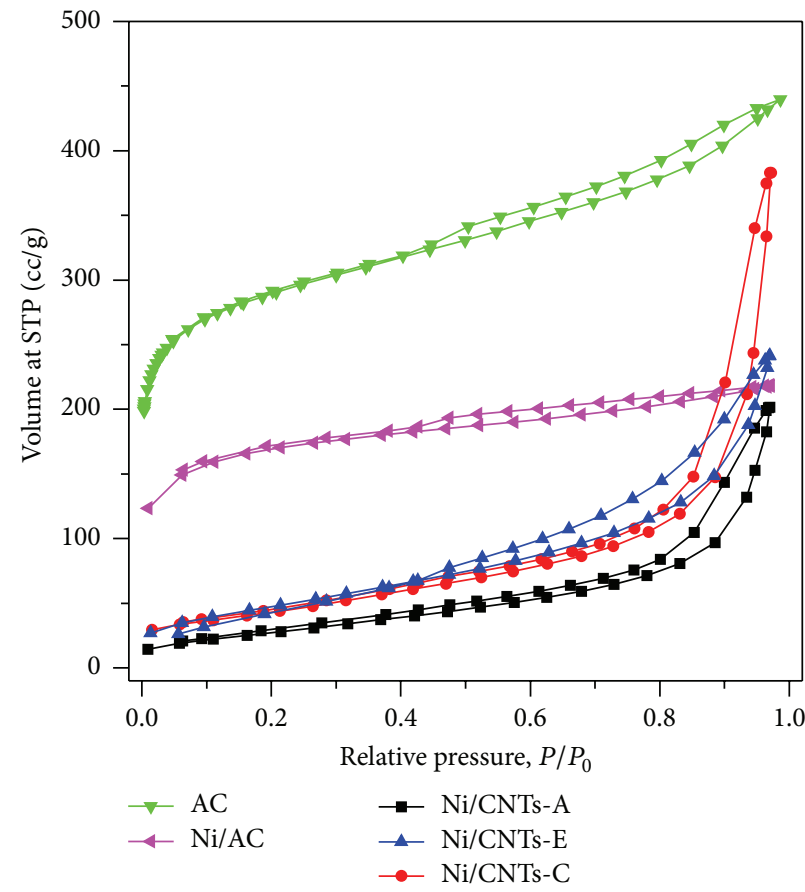

(a)

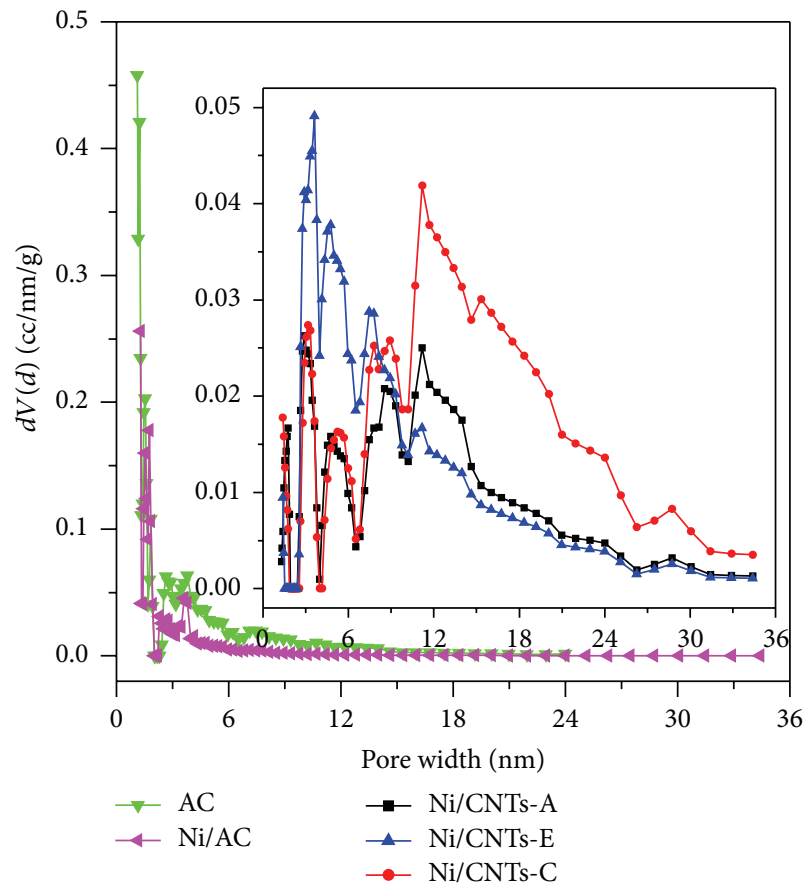

(b)

FIGURE 3: $\mathrm{N}_{2}$ adsorption/desorption isotherms (77 K) (a) and pore size distributions obtained applying the DFT equation (b) corresponding to the catalysts.

other catalysts, the specific surface area of Ni/AC catalyst was decreased significantly due to the existence of Ni. This would result in a low catalytic activity for the $\mathrm{CO}_{2}$ methanation using $\mathrm{Ni} / \mathrm{AC}$ as the catalyst.

The XRD analysis was carried out to investigate the crystal structure of the catalyst. As shown in Figure 4, it revealed that the diffraction peak at $26.2^{\circ}$ in the catalysts can be well indexed as the (002) reflection of graphite, and the graphite peak of CNTs-supported catalysts was much stronger and narrower than that of the AC-supported catalyst, indicating the crystallinity of CNTs-supported catalysts was high. Metallic Ni species existed in all the reduced samples, with diffraction peaks $44.5^{\circ}, 51.8^{\circ}$, and $76.5^{\circ}$. According to the crystal plane $\mathrm{Ni}$ (111), the particle size of metallic $\mathrm{Ni}$ in the 
TABLE 2: Structural characteristics of the catalysts.

\begin{tabular}{lccc}
\hline Sample & $S_{\text {BET }}\left(\mathrm{m}^{2} / \mathrm{g}\right)$ & $V_{t}\left(\mathrm{~cm}^{3} / \mathrm{g}\right)$ & $\begin{array}{c}\text { Average pore } \\
\text { diameter }(\mathrm{nm})\end{array}$ \\
\hline $\mathrm{AC}$ & 927.5 & 0.680 & 2.93 \\
$\mathrm{Ni} / \mathrm{AC}$ & 538.4 & 0.338 & 2.51 \\
$\mathrm{Ni} / \mathrm{CNTs}-\mathrm{A}$ & 103.1 & 0.312 & 12.09 \\
Ni/CNTs-C & 156.2 & 0.592 & 15.17 \\
Ni/CNTs-E & 174.7 & 0.373 & 8.55 \\
\hline
\end{tabular}

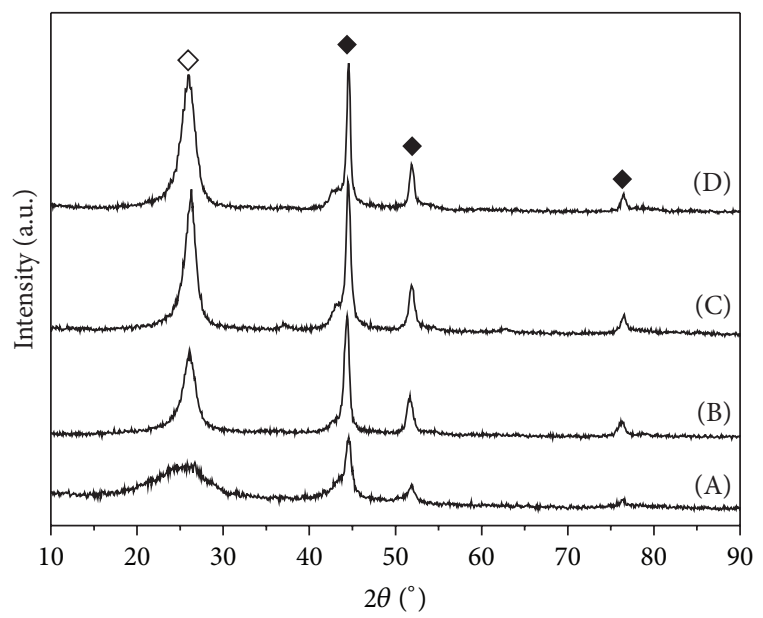
(A) $\mathrm{Ni} / \mathrm{AC}$
(D) Ni/CNTs-C
(B) Ni/CNTs-A
$\diamond$ Graphite
(C) Ni/CNTs-E
$\checkmark$ Metallic Ni

FIGURE 4: XRD profiles for the reduced catalysts.

catalysts was calculated by Scherrer equation. It was found that the particle size of metallic $\mathrm{Ni}$ was 8.9, 9.8, 10.3, and $11.3 \mathrm{~nm}$ for Ni/AC, Ni/CNTs-A, Ni/CNTs-E, and Ni/CNTs$\mathrm{C}$, respectively. Due to the largest specific surface area, ACsupported catalyst was favorable for the decrease of the particle size of Ni.

Temperature-programmed reduction of $\mathrm{H}_{2}\left(\mathrm{H}_{2}\right.$-TPR) is usually employed for estimating reducibility of the catalyst, and the results were displayed in Figure 5. Compared with $\mathrm{Ni} / \mathrm{AC}$, the interaction was weaker between CNTs and nickel species for Ni/CNTs series. The low reduction temperatures can be attributed to the overflow effect of hydrogen, which activated hydrogen molecules, thereby promoting the reduction reaction of hydrogen and nickel species at low temperatures. As seen from Figure 5, CNTs-E was to promote the reduction of the nickel species, proved by a significant increase in low temperature reduction.

3.3. Catalytic Performance. The activity of the catalysts was tested by measuring the conversion of $\mathrm{CO}_{2}$ and the yield of $\mathrm{CH}_{4}$ as a function of reaction temperature on stream. As shown in Figure 6, except for the catalyst Ni/CNTs-A, the CNTs-supported catalysts displayed better catalytic activity than the AC-supported catalyst, which can be attributed to the high $\mathrm{H}_{2}$ storage capacity of CNTs, thus promoting

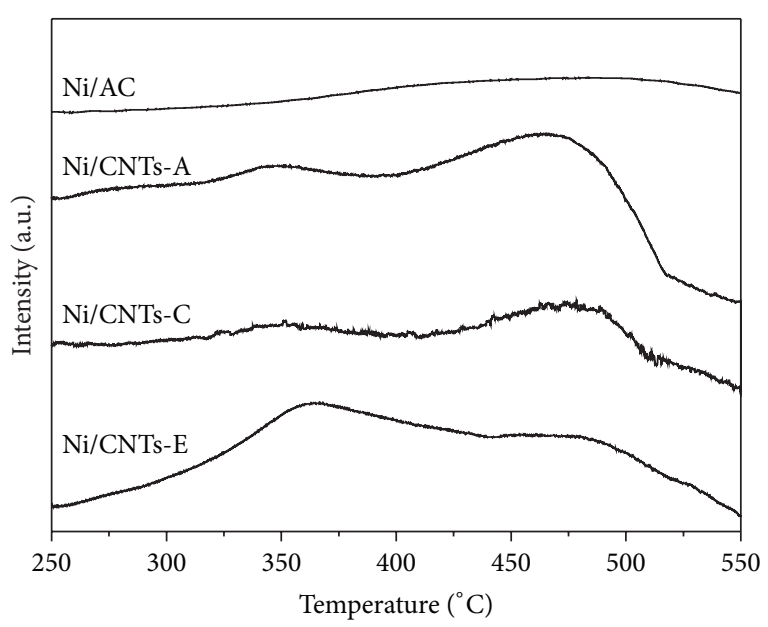

FIgURE 5: $\mathrm{H}_{2}$-TPR profiles of the catalysts prepared with different supports.

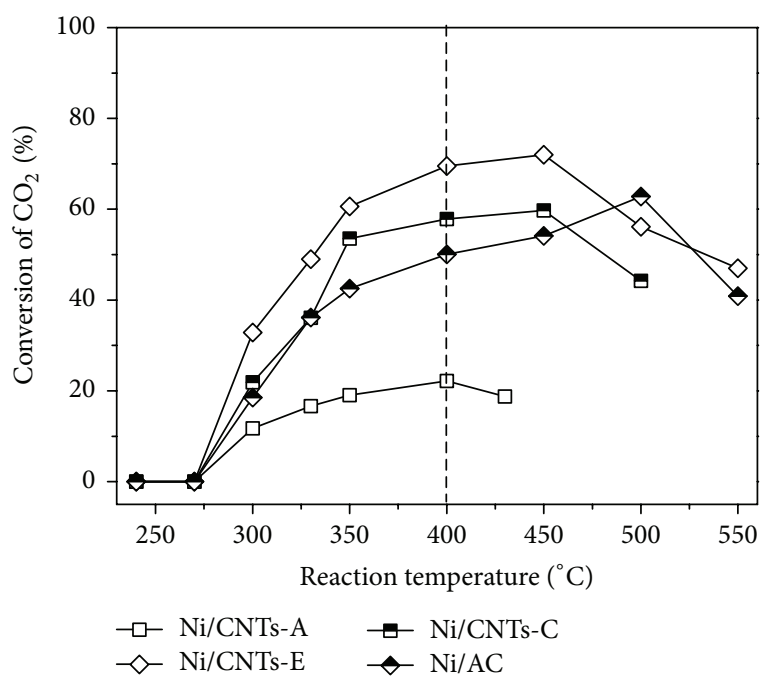

FIgURE 6: $\mathrm{CO}_{2}$ conversion versus reaction temperature on the catalysts.

the hydrogenation of $\mathrm{CO}_{2}$. Compared with $\mathrm{Ni} / \mathrm{AC}, \mathrm{Ni} / \mathrm{CNTs}-$ $\mathrm{E}$ catalyst had higher catalytic activity, but, with the reaction temperature increasing to $500^{\circ} \mathrm{C}, \mathrm{Ni} / \mathrm{CNTs}-\mathrm{E}$ had lower catalytic activity than that of Ni/AC. On the whole, the catalytic activity decreased in the following order: Ni/CNTs-E $>$ Ni/CNTs-C $>$ Ni/AC $>$ Ni/CNTs-A.

It revealed that the catalytic activity was improved not only by the specific surface area of the supports, for the specific surface area of CNTs-E, CNTs-C, CNTs-A, and AC was $254.1 \mathrm{~m}^{2} / \mathrm{g}, 179.0 \mathrm{~m}^{2} / \mathrm{g}, 118.1 \mathrm{~m}^{2} / \mathrm{g}$, and $927.5 \mathrm{~m}^{2} / \mathrm{g}$, respectively, but also by the overflow effect of hydrogen for CNTs supports. It was observed that the defects over the various CNTs samples have shown no obvious effects on the catalytic activity. For the CNTs supports, CNTs-A had lower defects than CNTs-E and CNTs-C. The catalyst Ni/CNTsA, with lower defects and specific surface area, showed the lowest catalytic activity among the CNTs-supported samples. 


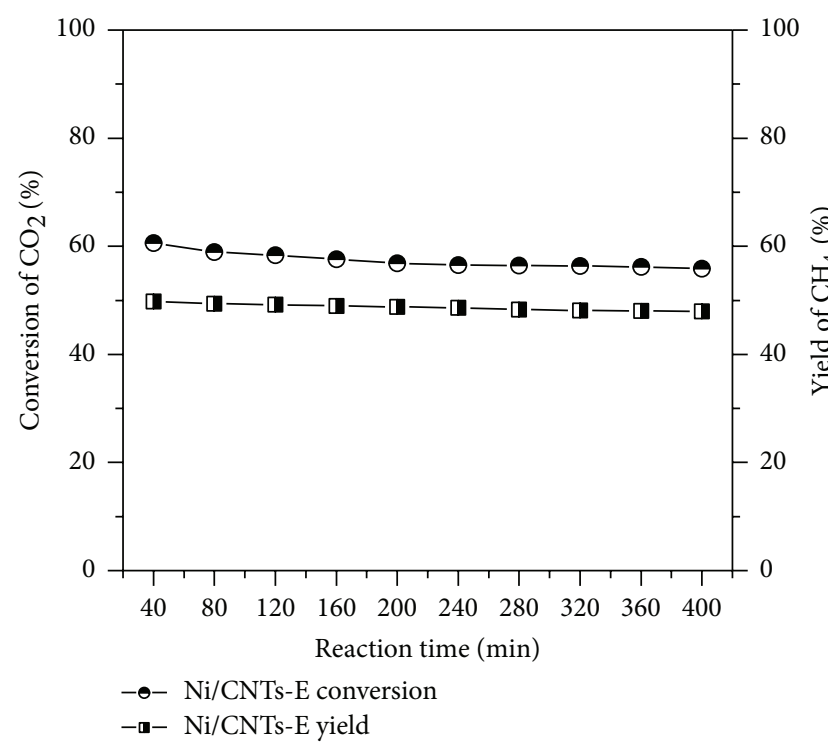

(a)

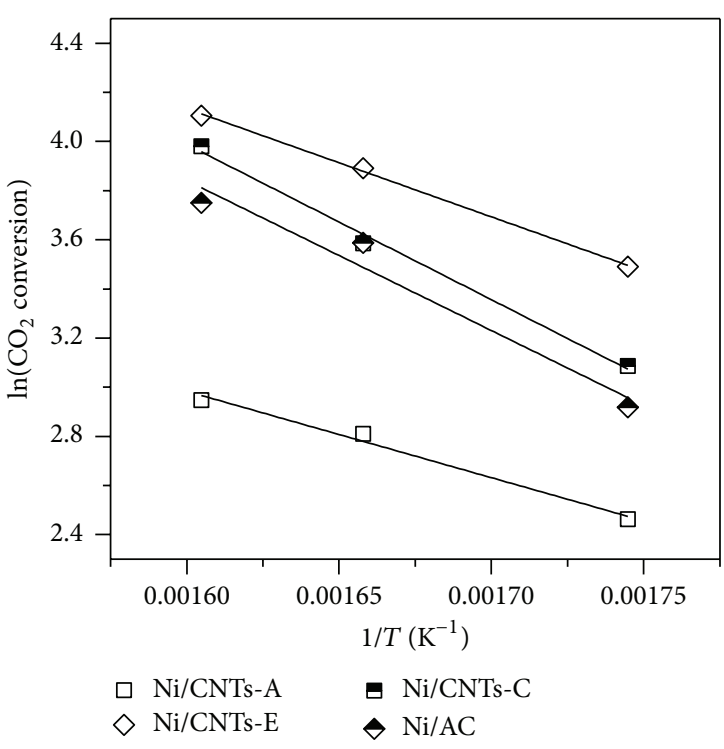

(b)

Figure 7: $\mathrm{CO}_{2}$ conversion and $\mathrm{CH}_{4}$ yield versus reaction time at $350^{\circ} \mathrm{C}$ (a) and logarithm of $\mathrm{CO}_{2}$ conversion versus the reciprocal of temperature (b) on the catalysts.

Herein, for Ni/CNTs-A, the catalytic activity was mainly lowered by the low specific surface area. The CNTs-E and CNTs$\mathrm{C}$ had similar textural properties, but CNTs-C possessed more defects in comparison to CNTs-E. Unexpectedly, the sample Ni/CNTs-C did not exhibit a higher catalytic activity. Hence, compared with the difference in pore structure, the defects played a minor role in catalytic performance of $\mathrm{Ni} / \mathrm{CNTs}$ for $\mathrm{CO}_{2}$ methanation.

Figure 7(a) displayed the catalytic stability of the catalyst $\mathrm{Ni} / \mathrm{CNTs}-\mathrm{E}$. With the reaction proceeding, the catalytic activity decreased slightly, which could be due to sintering of active component. Therefore, it is very important to find the catalyst additives which can improve the stability of the catalyst with low price. Figure 7(b) showed the relationship between logarithm of $\mathrm{CO}_{2}$ conversion and reciprocal of temperature. Based on Arrhenius formula, activation energies of the catalysts were calculated from the slope of the fitted lines. It was observed that the activation energy decreased for Ni/CNTs$\mathrm{A}$ and Ni/CNTs-E. The activation energies of the catalysts were $29.23,36.61,52.54$, and $50.77 \mathrm{KJ} / \mathrm{mol}$ for Ni/CNTs-A, $\mathrm{Ni} / \mathrm{CNTs}-\mathrm{E}, \mathrm{Ni} / \mathrm{CNTs}-\mathrm{C}$, and $\mathrm{Ni} / \mathrm{AC}$, respectively.

\section{Conclusions}

The nano Ni-based catalysts supported by CNTs with various textural characteristics were synthetized by impregnation method for $\mathrm{CO}_{2}$ methanation performance. The prepared CNTs were characterized by $\mathrm{N}_{2}$ adsorption/desorption, TGA, and Raman spectroscopy, respectively, in order to investigate the textural characteristics of the CNTs. The catalysts were determined by X-ray diffraction (XRD), $\mathrm{N}_{2}$ adsorption/desorption, and temperature-programmed reduction $\left(\mathrm{H}_{2}\right.$-TPR) techniques. The results showed that the textural characteristics of CNTs supports significantly impacted on the catalytic performance of Ni/CNTs, and the catalyst $\mathrm{Ni} / \mathrm{CNTs}-\mathrm{E}$ with good reducibility, large specific surface area, and moderate defects resulted in higher $\mathrm{CO}_{2}$ conversion and $\mathrm{CH}_{4}$ yield.

\section{Conflict of Interests}

The authors declare that there is no conflict of interests regarding the publication of this paper.

\section{Acknowledgment}

This work was supported by the National Basic Research Program of China (973 Program, no. 2011CB201202).

\section{References}

[1] F. Ocampo, B. Louis, A. Kiennemann, and A. C. Roger, " $\mathrm{CO}_{2}$ methanation over Ni-Ceria-Zirconia catalysts: effect of preparation and operating conditions," IOP Conference Series: Materials Science and Engineering, vol. 19, no. 1, Article ID 012007, 2011.

[2] S. Eckle, H.-G. Anfang, and R. J. Behm, "What drives the selectivity for $\mathrm{CO}$ methanation in the methanation of $\mathrm{CO}_{2}$-rich reformate gases on supported Ru catalysts?" Applied Catalysis A: General, vol. 391, no. 1-2, pp. 325-333, 2011.

[3] S. Sharma, Z. Hu, P. Zhang, E. W. McFarland, and H. Metiu, "CO $\mathrm{CO}_{2}$ methanation on Ru-doped ceria," Journal of Catalysis, vol. 278, no. 2, pp. 297-309, 2011.

[4] A. Borgschulte, N. Gallandat, B. Probst et al., "Sorption enhanced $\mathrm{CO}_{2}$ methanation," Physical Chemistry Chemical Physics, vol. 15, no. 24, pp. 9620-9625, 2013.

[5] W. Cai, Q. Zhong, and Y. Zhao, "Fractional-hydrolysisdriven formation of non-uniform dopant concentration catalyst nanoparticles of Ni/Ce $\mathrm{Zr}_{1-x} \mathrm{O}_{2}$ and its catalysis in methanation of $\mathrm{CO}_{2}$," Catalysis Communications, vol. 39, pp. 30-34, 2013. 
[6] S. Hwang, U. G. Hong, J. Lee et al., "Methanation of carbon dioxide over mesoporous $\mathrm{Ni}-\mathrm{Fe}-\mathrm{Al}_{2} \mathrm{O}_{3}$ catalysts prepared by a coprecipitation method: effect of precipitation agent," Journal of Industrial and Engineering Chemistry, vol. 19, no. 6, pp. 20162021, 2013.

[7] A. Karelovic and P. Ruiz, " $\mathrm{CO}_{2}$ hydrogenation at low temperature over $\mathrm{Rh} / \gamma-\mathrm{Al}_{2} \mathrm{O}_{3}$ catalysts: effect of the metal particle size on catalytic performances and reaction mechanism," Applied Catalysis B: Environmental, vol. 113-114, pp. 237-249, 2012.

[8] K. Müller, M. Städter, F. Rachow, D. Hoffmannbeck, and D. Schmeißer, "Sabatier-based $\mathrm{CO}_{2}$-methanation by catalytic conversion," Environmental Earth Sciences, vol. 70, no. 8, pp. 3771-3778, 2013.

[9] X. F. Hu, W. Yang, N. Wang, S.-Z. Luo, and W. Chu, "Catalytic properties of Ni/CNTs and Ca-promoted Ni/CNTs for methanation reaction of carbon dioxide," Advanced Materials Research, vol. 924, pp. 217-226, 2014.

[10] Y. Y. Feng, C. F. Jiang, D. J. Liu, and W. Chu, "Experimental investigations on microstructure and adsorption property of heat-treated coal chars," Journal of Analytical and Applied Pyrolysis, vol. 104, pp. 559-566, 2013.

[11] W. Yang, Y. Y. Feng, and W. Chu, "Comparative study of textural characteristics on methane adsorption for carbon spheres produced by $\mathrm{CO}_{2}$ activation," International Journal of Chemical Engineering, vol. 2014, Article ID 916913, 7 pages, 2014.

[12] A. Karelovic and P. Ruiz, "Mechanistic study of low temperature $\mathrm{CO}_{2}$ methanation over $\mathrm{Rh} / \mathrm{TiO}_{2}$ catalysts," Journal of Catalysis, vol. 301, pp. 141-153, 2013.

[13] F. Ocampo, B. Louis, L. Kiwi-Minsker, and A.-C. Roger, "Effect of $\mathrm{Ce} / \mathrm{Zr}$ composition and noble metal promotion on nickel based $\mathrm{Ce}_{\mathrm{x}} \mathrm{Zr}_{1-\mathrm{x}} \mathrm{O}_{2}$ catalysts for carbon dioxide methanation," Applied Catalysis A: General, vol. 392, no. 1-2, pp. 36-44, 2011.

[14] H. Takano, K. Izumiya, N. Kumagai, and K. Hashimoto, "The effect of heat treatment on the performance of the $\mathrm{Ni} /(\mathrm{Zr}-$ Sm oxide) catalysts for carbon dioxide methanation," Applied Surface Science, vol. 257, no. 19, pp. 8171-8176, 2011.

[15] G. Zhi, X. Guo, X. Guo, Y. Wang, and G. Jin, "Effect of $\mathrm{La}_{2} \mathrm{O}_{3}$ modification on the catalytic performance of $\mathrm{Ni} / \mathrm{SiC}$ for methanation of carbon dioxide," Catalysis Communications, vol. 16, no. 1, pp. 56-59, 2011.

[16] D. C. D. da Silva, S. Letichevsky, L. E. P. Borges, and L. G. Appel, "The $\mathrm{Ni} / \mathrm{ZrO}_{2}$ catalyst and the methanation of $\mathrm{CO}$ and $\mathrm{CO}_{2}$," International Journal of Hydrogen Energy, vol. 37, no. 11, pp. 8923-8928, 2012.

[17] A. Beuls, C. Swalus, M. Jacquemin, G. Heyen, A. Karelovic, and P. Ruiz, "Methanation of $\mathrm{CO}_{2}$ : further insight into the mechanism over $\mathrm{Rh} / \gamma-\mathrm{Al}_{2} \mathrm{O}_{3}$ catalyst," Applied Catalysis $\mathrm{B}$ : Environmental, vol. 113-114, pp. 2-10, 2012.

[18] C. Swalus, M. Jacquemin, C. Poleunis, P. Bertrand, and P. Ruiz, " $\mathrm{CO}_{2}$ methanation on $\mathrm{Rh} / \gamma-\mathrm{Al}_{2} \mathrm{O}_{3}$ catalyst at low temperature: 'in situ' supply of hydrogen by $\mathrm{Ni}$ /activated carbon catalyst," Applied Catalysis B: Environmental, vol. 125, pp. 41-50, 2012.

[19] A. Karelovic and P. Ruiz, "Improving the hydrogenation function of $\mathrm{Pd} / \gamma-\mathrm{Al}_{2} \mathrm{O}_{3}$ catalyst by $\mathrm{Rh} / \gamma-\mathrm{Al}_{2} \mathrm{O}_{3}$ addition in $\mathrm{CO}_{2}$ methanation at low temperature," ACS Catalysis, vol. 3, no. 12, pp. 2799-2812, 2013.

[20] S. Tada, T. Shimizu, H. Kameyama, T. Haneda, and R. Kikuchi, " $\mathrm{Ni} / \mathrm{CeO}_{2}$ catalysts with high $\mathrm{CO}_{2}$ methanation activity and high $\mathrm{CH}_{4}$ selectivity at low temperatures," International Journal of Hydrogen Energy, vol. 37, no. 7, pp. 5527-5531, 2012.

[21] W. Yang, W. Chu, C. Jiang, J. Wen, and W. Sun, "Cerium oxide promoted $\mathrm{Ni} / \mathrm{MgO}$ catalyst for the synthesis of multi-walled carbon nanotubes," Chinese Journal of Catalysis, vol. 32, no. 8, pp. 1323-1328, 2011.

[22] W. J. Sun, Z. Q. Liu, C. F. Jiang, Y. Xue, W. Chu, and X. S. Zhao, "Experimental and theoretical investigation on the interaction between palladium nanoparticles and functionalized carbon nanotubes for Heck synthesis," Catalysis Today, vol. 212, pp. 206-214, 2013.

[23] J. M. Planeix, N. Coustel, B. Coq et al., "Application of carbon nanotubes as supports in heterogeneous catalysis," Journal of the American Chemical Society, vol. 116, no. 17, pp. 7935-7936, 1994.

[24] R. Zacharia, K. Y. Kim, A. K. M. Fazle Kibria, and K. S. Nahm, "Enhancement of hydrogen storage capacity of carbon nanotubes via spill-over from vanadium and palladium nanoparticles," Chemical Physics Letters, vol. 412, no. 4-6, pp. 369-375, 2005.

[25] P.-X. Hou, S.-T. Xu, Z. Ying, Q.-H. Yang, C. Liu, and H.-M. Cheng, "Hydrogen adsorption/desorption behavior of multiwalled carbon nanotubes with different diameters," Carbon, vol. 41, no. 13, pp. 2471-2476, 2003.

[26] L. Smędowski, M. Krzesińska, W. Kwaśny, and M. Kozanecki, "Development of ordered structures in the high-temperature (HT) cokes from binary and ternary coal blends studied by means of X-ray diffraction and Raman spectroscopy," Energy \& Fuels, vol. 25, no. 7, pp. 3142-3149, 2011.

[27] Y.-Y. Feng, C.-F. Jiang, D.-J. Liu, and W. Chu, "Microstructure and its influence on $\mathrm{CH}_{4}$ adsorption behavior of deep coal," Chinese Physics B, vol. 23, no. 2, Article ID 028201, 2014. 

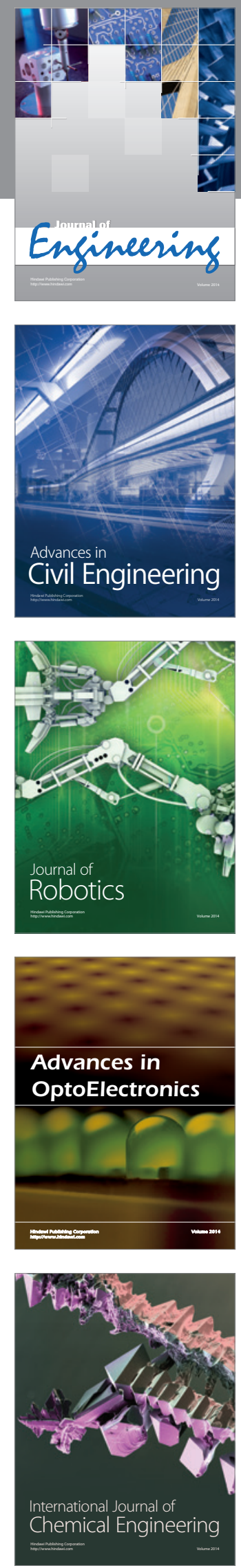

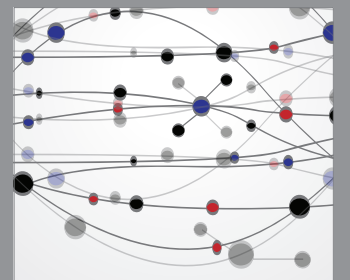

The Scientific World Journal
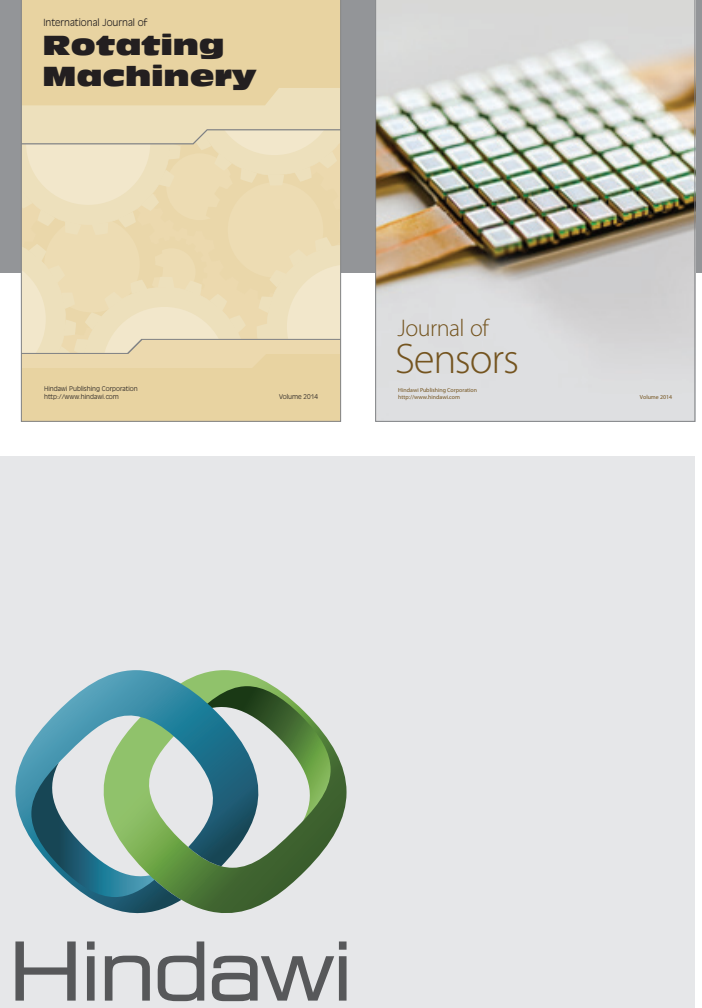

Submit your manuscripts at http://www.hindawi.com
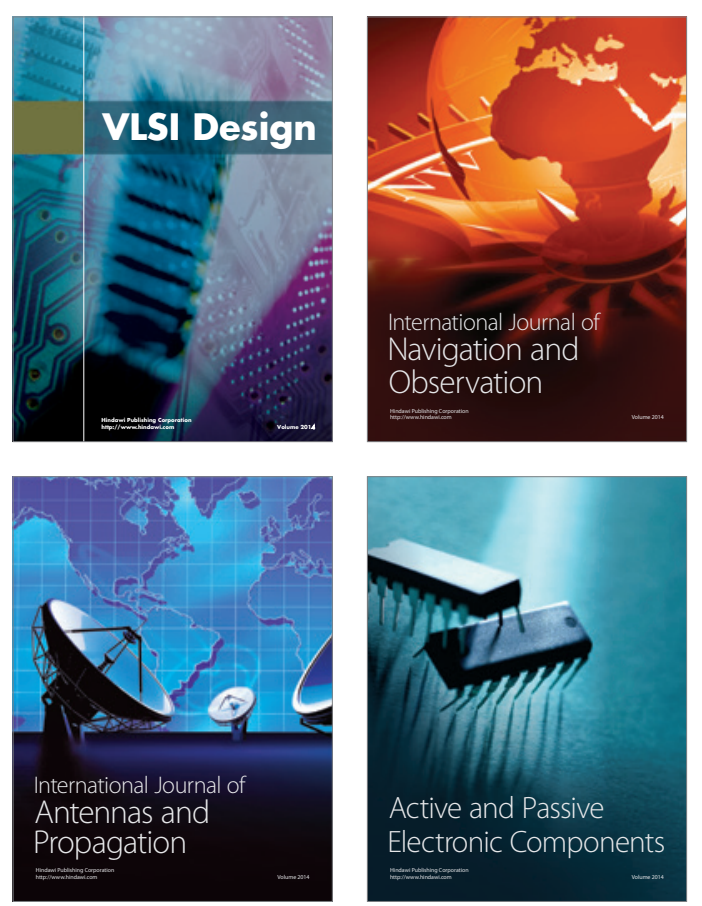
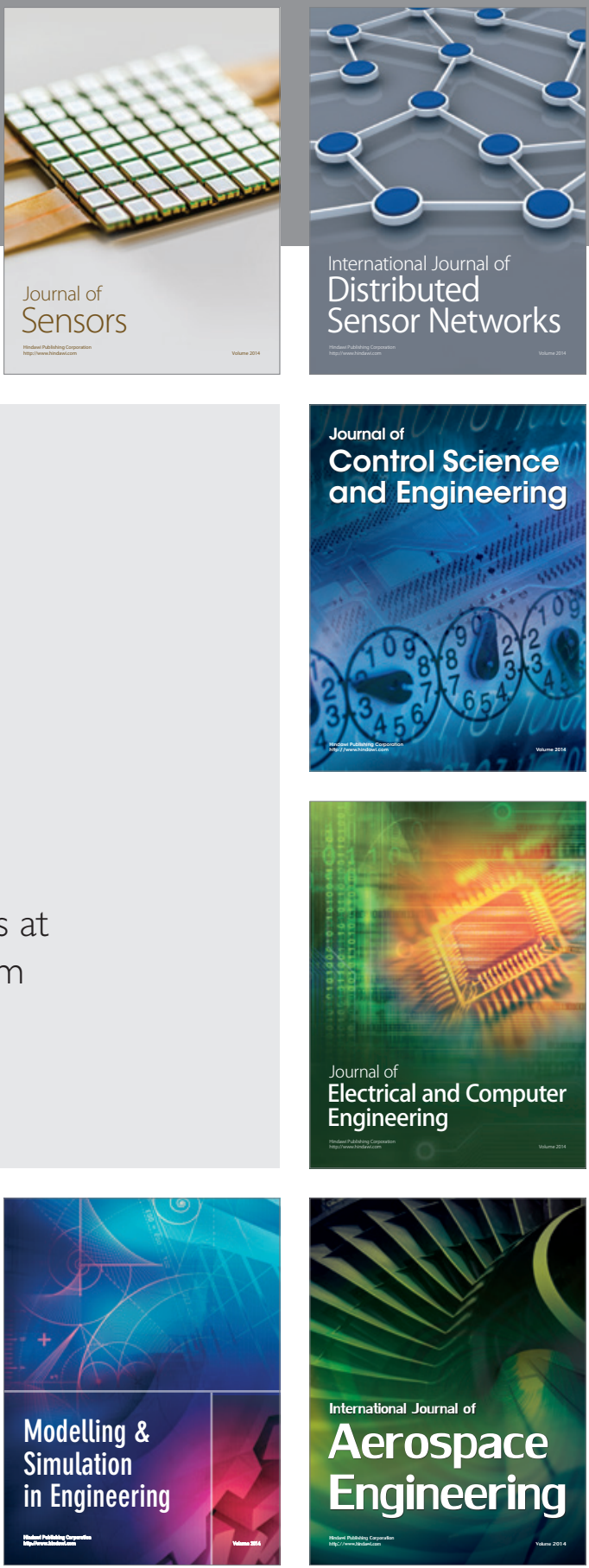

Journal of

Control Science

and Engineering
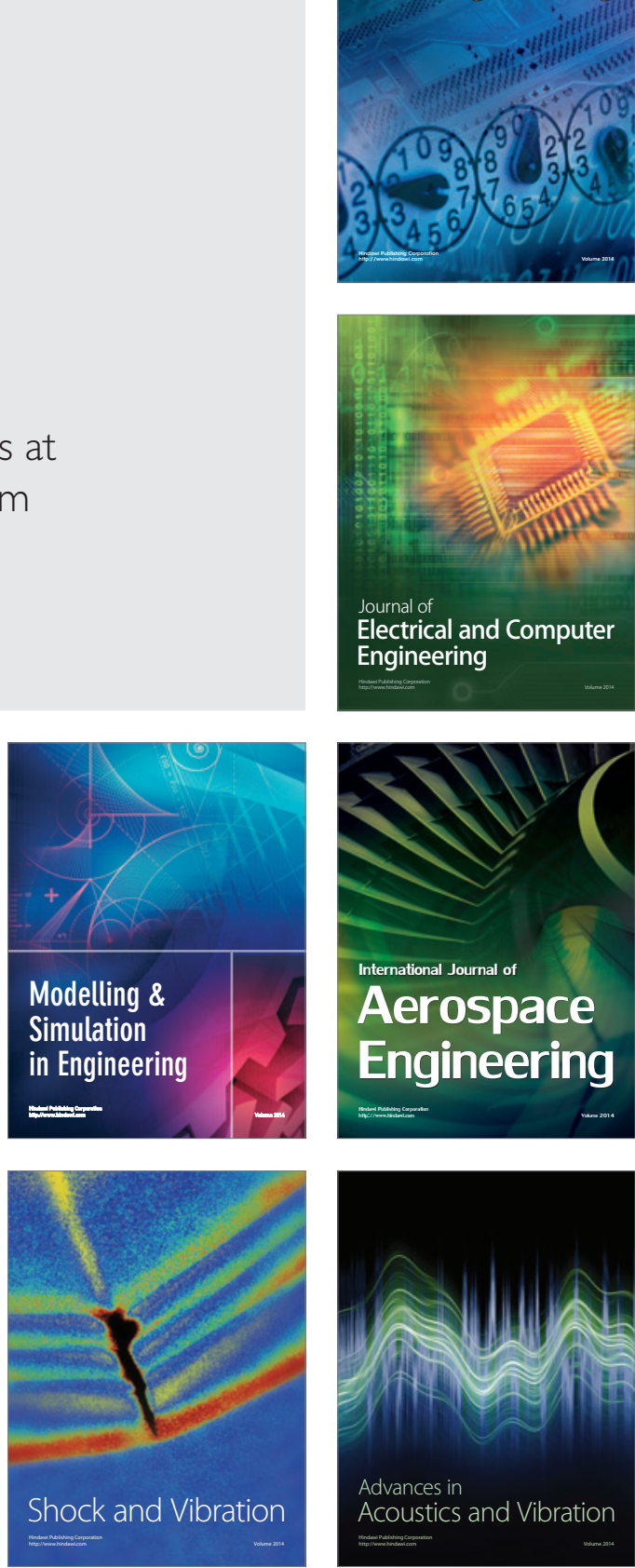